\title{
Manejo de ordenha como fator de risco na ocorrência de micro- organismos em leite cru
}

\section{Handling milking as a risk factor in the occurrence of microorganisms in raw milk}

\author{
Tony Picoli ${ }^{1}$; João Luíz Zani²; Fernando da Silva Bandeira ${ }^{2}$; \\ Victor Fernando Büttow Roll'3; Maria Edi Rocha Ribeiro'; \\ Gilberto D’Ávila Vargas²; Silvia Oliveira Hübner²; Marcelo de Lima²; \\ Mário Carlos Araújo Meireles ${ }^{2}$; Geferson Fischer ${ }^{2 *}$
}

\begin{abstract}
Resumo
O leite é um alimento natural e rico em nutrientes, porém a forma como muitas vezes é obtido interfere na sua qualidade microbiológica e nutricional. E a qualidade dos produtos é uma exigência cada vez maior do mercado consumidor. Assim, objetivou-se identificar micro-organismos presentes no leite de tanques resfriadores, na região sul do Rio Grande do Sul, e estabelecer uma correlação entre o manejo dos animais e sua presença no tanque. Foram coletadas amostras de leite em propriedades de seis municípios e realizadas análises microbiológicas para identificação microbiana. As médias das contagens foram: Staphylococcus sp. $5,32 \times 10^{6} \mathrm{UFC} / \mathrm{mL}$, S. aureus $1,33 \times 10^{5} \mathrm{UFC} / \mathrm{mL}$, enterobactérias $1,82 \times 10^{7} \mathrm{UFC} /$ $\mathrm{mL}$. Houve presença de Escherichia coli (27,8\% das propriedades), Streptococcus agalactiae (6,2\%), S. dysgalactiae (37,2\%), S. uberis (16,8\%), Candida sp. (15,7\%), Aspergillus sp. (5,8\%), Trichosporum sp. (3,6\%) e Cryptococcus sp. (1,5\%). Identificou-se uma Odds Ratio de 3,2 para S. agalactiae com relação à ordenha manual e de 3,1 quando um único pano era usado para secagem dos tetos. Para $S$. dysgalactiae houve 55,8\% de probabilidade da ocorrência em caso de não secagem dos tetos. Para $S$. bovis, uma Odds Ratio de 2,8 em propriedades que ordenham seus animais em estábulos de madeira. Houve aumento significativo $(\mathrm{p}=0,003)$ na contagem de células somáticas (CCS) de propriedades que realizam ordenha manual em relação àquelas mecanizadas. A ordenha manual aumentou as contagens de S. aureus $(\mathrm{p}=0,04)$. A realização de pré-dipping contribuiu para a redução da contagem de Staphylococcus sp. e houve diferença significativa em relação ao grupo que não realizava esta prática $(\mathrm{p}=0,04)$. Conclui-se que as técnicas de manejo mais precárias influenciam negativamente na qualidade microbiológica do leite, aumentando os riscos de ocorrência de agentes infecciosos e elevando as contagens de micro-organismos. Palavras-chave: Qualidade microbiológica, leite, Staphylococcus, Streptococcus
\end{abstract}

\footnotetext{
Abstract

Milk is naturally a good provider of a whole range of nutrients, however an inadequate milking may significantly interfere on its nutritional and microbiological quality. The main purpose of this study was

${ }^{1}$ Discente de Doutorado em Veterinária, Universidade Federal de Pelotas, UFPel, Pelotas, RS. E-mail: picolivet@gmail.com

${ }^{2}$ Profs.do Dept ${ }^{\circ}$ de Veterinária Preventiva,UFPel,Pelotas, RS.E-mail:jluizzani@ig.com.br; bandeiravett@gmail.com; gdavilavargas@ gmail.com; sohubner@yahoo.com.br; mdelima.ufpel@gmail.com; meireles@ufpel.edu.br; geferson.fischer@gmail.com

${ }^{3}$ Prof. do Dept ${ }^{\circ}$ Zootecnia, UFPel, Pelotas, RS. E-mail: roll2@hotmail.com

${ }^{4}$ Pesquisador, Empresa Brasileira de Pesquisa Agropecuária, EMBRAPA, Clima Temperado, Pelotas, RS. E-mail: maria.edi@ cpact.embrapa.br

* Autor para correspondência
} 
to isolate and identify microorganisms from bulk tanks of southern Rio Grande do Sul state, Brazil and establish a correlation between animal management and presence of pathogens in the milk. To this end, raw milk samples were collected from different dairy herds and submitted to microbiological analyses. Mean bacterial counts were Staphylococcus sp. $\left(5,32 \times 10^{6} \mathrm{CFU} / \mathrm{mL}\right)$, S. aureus $\left(1,33 \times 10^{5} \mathrm{CFU} / \mathrm{mL}\right)$ and enterobacteria $\left(1,82 \times 10^{7} \mathrm{CFU} / \mathrm{mL}\right)$. The major pathogens isolated and their respective frequency were Escherichia coli (27.8\%), Streptococcus agalactiae (6.2\%), S. dysgalactiae (37.2\%), S. uberis (16.8\%), Candida sp. (15.7\%), Aspergillus sp. (5.8\%), Trichosporum sp. (3.6\%) and Cryptococcus sp. (1.5\%). In addition, it was identified an Odds Ratio of 3.2 for $S$. agalactiae regarding manual milking and 3.1 when a single cloth towel was used for drying the udder. For S. bovis the Odds Ratio was 2.8 in properties milking their animals in stalls wood. Somatic cell count (SCC) was significantly higher $(\mathrm{p}=0,003)$ in milk samples manually extracted in comparison with machine milking. Likewise, manual milking resulted in the increase in $S$. aureus counts $(\mathrm{p}=0.04)$. Pre-dipping practice have contributed for a significant reduction $(\mathrm{p}=0.04)$ in the Staphylococcus sp. counts. Taken together, our results show that the adoption of poor management practices can negatively interfere in the microbiological quality of milk increasing the risks of occurrence of pathogens and their counts.

Key words: Microbiological quality, milk, Staphylococcus, Streptococcus

\section{Introdução}

O mercado do leite atravessa um período de mudanças, uma vez que a remuneração deste produto pela indústria passa a ser realizada de acordo com as novas exigências referentes à qualidade do leite previstas nas novas legislações (BRASIL, 2011), afetando tanto o produtor quanto a indústria. Por outro lado, a seguridade alimentar também merece destaque, pois o consumidor, cada vez mais, exige alimentos saudáveis. Assim, o produtor necessita alterar a forma de obtenção do leite, que vem sendo praticada há décadas, a fim de adequar-se às legislações e às exigências do mercado consumidor e, ainda assim, manter a atividade rentável.

O leite é um alimento natural e rico em nutrientes, mas sua qualidade é afetada pela higiene, pela forma como a ordenha é realizada, pela limpeza do equipamento e pela saúde da glândula mamária, que tem como principal enfermidade, a mastite (FONSECA; SANTOS, 2000). Esta infecção da glândula mamária é a doença mais frequente no gado leiteiro, levando a prejuízos econômicos, dentre outros, pela queda no volume produzido e na qualidade, aumentando os custos de produção e diminuição do rendimento da indústria (BRESSAN, 2000).

As principais causas de mastites são as infecciosas e, dentre estas, os patógenos bacterianos são os maiores causadores, seguidos dos patógenos fúngicos. De acordo com a origem do agente, a mastite pode ser classificada em dois grupos: contagiosa e ambiental. Os organismos contagiosos são adaptados à vida no interior da glândula mamária e, geralmente, são transmitidos no momento da ordenha. Nesse grupo, destacam-se Staphylococcus aureus e Streptococcus agalactiae. Em contraste, os patógenos ambientais como Escherichia coli e o Streptococcus uberis são melhor descritos como invasores oportunistas do úbere, e tem origem no ambiente, como o solo contaminado (WATTS, 1988).

Já os patógenos fúngicos são cada vez mais descritos como causadores de mastite e a terapia antibacteriana intra-mamária facilita o aparecimento de mastite causada por leveduras. A maioria dos isolados pertencem aos gêneros Candida, Cryptococcus, Aspergillus e Trichosporum (RUZPERES et al., 2004).

As mastites também são classificadas, de acordo com a sua manifestação, em clínica, apresentando sinais clínicos, ou subclínica, sem sinais visíveis no leite ou no úbere. Independente da forma de apresentação, a mastite causa alterações na composição do leite, aumento da presença de microorganismos e da contagem de células somáticas (CCS), que é indicador da saúde da glândula 
mamária. Barbalho e Mota (2001) relatam que a mastite subclínica apresenta maior importância epidemiológica por alastrar-se silenciosamente pelo rebanho sem que sejam percebidas alterações no úbere ou em sua secreção. Ribeiro et al. (2003) e Meyer et al. (2013) estimaram uma prevalência de mastite subclínica na região de Pelotas de $37,69 \%$ e $37,4 \%$, respectivamente, indicando que os índices da enfermidade nesta região têm se mantido constante.

Para prevenção e controle da enfermidade nos rebanhos, Radostits et al. (2002) sugerem medidas de manejo de ordenha, principalmente a correta ordem de ordenha das vacas, realização do pré e pósdipping e a higiene das instalações, equipamentos e do ordenhador. A higiene dos processos de obtenção do leite pode ser monitorada através da Contagem Bacteriana Total (CBT), e este é o maior problema encontrado na produção de leite (CERQUEIRA et al., 2006).

Objetivou-se, com este estudo, identificar microorganismos presentes no leite obtido de tanques resfriadores, da região sul do Rio Grande do Sul, e relacioná-los com as diferentes técnicas de manejo adotadas nas Unidades de Produção Leiteiras (UPL).

\section{Material e Métodos}

Foram visitadas 274 unidades de produção de leite (UPL) em seis municípios da região sul do Rio Grande do Sul (RS): 65 no município de Pelotas, 69 em Canguçu, 16 em Rio Grande, 62 em Cerrito, 37 em Morro Redondo e 25 em São Lourenço do Sul. Foram realizados questionários epidemiológicos com os responsáveis pela atividade leiteira, abordando assuntos como o manejo nutricional, sanitário e reprodutivo das vacas leiteiras, manejo e higiene de ordenha e os cuidados na armazenagem do leite.

\section{Coleta de amostras}

Em cada UPL avaliada foram coletadas três amostras de leite de aproximadamente $50 \mathrm{~mL}$ dos tanques resfriadores, homogeneizadas com mexedor inoxidável de cabo longo imerso em álcool entre as coletas, em recipientes de poliestireno estéreis identificados. Foi utilizado um copo coletor inoxidável imerso em álcool $70^{\circ} \mathrm{GL}$ entre cada uma das coletas. Um dos recipientes continha conservante bronopol (2bromo-2nitropropano1,3diol), outro continha azidiol (azida sódica e cloranfenicol) e a terceira amostra, coletada sem conservantes. As amostras foram armazenadas em caixas isotérmicas com temperatura não superior a $6^{\circ} \mathrm{C}$ até a chegada no laboratório.

\section{Contagem de células somáticas e contagem bacteriana total}

As duas amostras contendo conservantes foram encaminhadas ao Laboratório de Qualidade de Leite da Empresa Brasileira de Pesquisa Agropecuária - EMBRAPA - Clima Temperado. A amostra contendo bronopol foi destinada à $\mathrm{CCS}$, e a outra amostra, contendo azidiol, foi destinada à CBT. Ambas as análises foram realizadas através de contagem eletrônica por citometria de fluxo.

\section{Análise bacteriológica}

A terceira amostra, coletada sem conservantes, foi encaminhada ao Laboratório de Bacteriologia e Saúde Populacional da Faculdade de Veterinária, da Universidade Federal de Pelotas, para análise bacteriológica.Os meios de cultura utilizados foram Agar Baird-Parker (Acumedia ${ }^{\circledR}$ ), Agar Manitol Sal (Himedia $\left.{ }^{\circledR}\right)$, Agar Mac Conkey (Acumedia ${ }^{\circledR}$ ) e Agar Eosina-Azul de Metileno (EMB) (Himedia $\left.{ }^{\circledR}\right) . \quad O$ Meio de Edwards, modificado, foi preparado de acordo com Turnes (1970). As amostras de leite foram submetidas a quatro diluições decimais em salina estéril. A semeadura foi feita por espalhamento segundo Prescott, Harley e Klein (2002), de todas as diluições em duplicata e incubadas à temperatura de $37^{\circ} \mathrm{C}$, em aerobiose, por $24-48$ horas. 
Contagens, identificação e caracterização bacteriana

As colônias características de $S$. aureus em Agar Manitol Sal, E. coli em EMB Agar e colônias características de Streptococcus spp. em meio de Edwards, foram repicadas em Agar sangue com $5 \%$ de sangue ovino desfibrinado, e mantidas sob aerobiose em estufa bacteriológica a $37^{\circ} \mathrm{C}$ por 24 horas. Estas amostras foram submetidas à coloração de Gram, e aquelas que apresentaram características morfo-tintoriais típicas, foram submetidas a testes bioquímicos, segundo Quinn et al. (2005).

\section{Análise micológica}

Uma alíquota da amostra coletada sem conservantes foi encaminhada sob temperatura inferior a $6^{\circ} \mathrm{C}$ ao Centro de Diagnóstico e Pesquisa em Micologia Veterinária - MICVET -UFPel, onde $100 \mu \mathrm{L}$ de leite foi semeado por espalhamento em Agar Sabouraud dextrose com cloranfenicol, em duplicata. As placas foram incubadas em estufa durante 48 horas a $35^{\circ} \mathrm{C}$, em aerobiose (ARAÚJO et al., 2001). A identificação foi realizada utilizando o sistema Vitek2 (BioMérieux).

\section{Análise estatística}

Foi realizado o teste de Levene para determinação da homogeneidade das amostras e, após, realizado teste $t$ de Student para comparação entre médias não relacionadas com nível de significância de $95 \%$ $(\mathrm{p}<0,05)$. Para a variável independente relacionada com o tipo de secagem do teto com mais de duas possíveis respostas foi utilizada análise de variância com comparação entre médias pelo teste de Tukey, considerando um nível de significância de 95\% $($ p $<0,05)$. As pesquisas de E. coli, estreptococos e de fungos foram submetidas à análise de regressão logística com nível de significância de 95\%. Foi determinada a probabilidade de ocorrência desses micro-organismos de acordo com as técnicas de manejo de ordenha e tipos de instalações através da estimativa do risco relativo (Odds Ratio).

Todas as análises foram realizadas pelo programa estatístico Statistical Analysis System (SAS INSTITUTE, 2004).

\section{Resultados}

Os resultados das contagens de unidades formadoras de colônias em meios de cultura Agar Baird-Parker, Agar Manitol Sal e Agar Mac Conkey, são apresentados na Tabela 1 . O crescimento de colônias características de Staphylococcus spp. foi observado em $100 \%$ das amostras de leite cru. A contagem deste micro-organismo variou de 5,32 $\times 10^{2}$ $\mathrm{UFC} / \mathrm{mL}$ de leite a $5,92 \times 10^{4} \mathrm{UFC} / \mathrm{mL}$, e a contagem

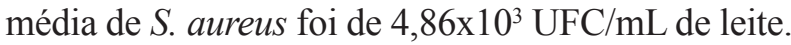

A média da contagem dos micro-organismos da família Enterobacteriacceae presentes no leite cru nos municípios estudados é apresentada na Tabela 1 , e teve média de $3,96 \times 10^{5} \mathrm{UFC} / \mathrm{mL}$ de leite. A espécie $E$. coli foi isolada em $27,8 \%$ das UPL visitadas.

Tabela 1. Médias das contagens bacterianas no leite de tanques resfriadores de municípios da região sul do Rio Grande do Sul, no ano de 2012.

\begin{tabular}{lccc}
\hline \multicolumn{1}{c}{ Micro-organismo } & Min $(\mathrm{UFC} / \mathrm{mL})$ & Max $(\mathrm{UFC} / \mathrm{mL})$ & Média $(\mathrm{UFC} / \mathrm{mL})$ \\
\hline Staphylococcus spp. & $3 \times 10^{2}$ & $5,32 \times 10^{6}$ & $5,92 \times 10^{4}$ \\
S. aureus & 0 & $1,33 \times 10^{5}$ & $4,86 \times 10^{3}$ \\
Enterobacteriacceae & 0 & $1,82 \times 10^{7}$ & $3,96 \times 10^{5}$ \\
\hline
\end{tabular}

Min - menor contagem observada,

Max- maior contagem observada.

Fonte: Elaboração dos autores. 
Quanto à presença dos Streptococcus spp, importantes na etiologia das mastites, e os isolamentos fúngicos, as frequências encontramse alocadas na Tabela 2. Streptococcus agalactiae foi isolado em $6,2 \%$ das UPL, Streptococcus dysgalactiae (37,2\% das UPL), Streptococcus uberis (16,8\% das UPL) e Streptococcus bovis $(6,9 \%$ das UPL). A Tabela 2 ainda apresenta as prevalências de fungos isolados nas amostras de leite cru da região de estudo, com destaque para leveduras do gênero Candida, que foram isoladas em $15,7 \%$ das UPL avaliadas.

Tabela 2. Frequências de Streptococcus spp. e fungos isolados em leite cru em 274 propriedades leiteiras da região sul do Rio Grande do Sul, no ano de 2012.

\begin{tabular}{lc}
\hline \multicolumn{1}{c}{ Micro-organismo } & \% de isolamentos \\
\hline S. agalactiae & 6,2 \\
S. dysgalactiae & 37,2 \\
S. uberis & 16,8 \\
S. bovis & 6,9 \\
Candida sp. & 15,7 \\
Trichosporum sp. & 3,6 \\
Aspergillus $\mathrm{sp}$. & 5,8 \\
Cryptococcus $\mathrm{sp}$. & 1,5 \\
\hline
\end{tabular}

Fonte: Elaboração dos autores.

Os fatores de risco da ocorrência dos microorganismos pesquisados, determinados pela
Odds Ratio, estão dispostos na Tabela 3. Houve maior chance de ocorrência (3,2 vezes maior) de $S$. agalactiae quando se utiliza ordenha manual ao invés de mecanizada $(p=0,042)$. O tipo de secagem do teto desempenhou papel importante na ocorrência de Streptococcus spp. e os dados obtidos neste estudo demonstram que há 3,1 vezes mais chances $(\mathrm{p}<0,05)$ da ocorrência de $S$. agalactiae quando se utiliza pano ao invés do papel toalha para secagem dos tetos. Já na comparação entre o uso do papel toalha e a ausência de secagem, houve um resultado interessante, que demonstra que há mais possibilidade ( 1,6 vezes mais chances $(\mathrm{p}<0,05))$ da ocorrência de $S$. agalactiae quando se utiliza papel. A secagem dos tetos também afetou a ocorrência de $S$. dysgalactiae, pois quando se compara o uso do papel toalha com a ausência de secagem, houve uma Odds Ratio de $0,442(\mathrm{p}<0,05)$. Houve 2,8 vezes mais chance de ocorrência de $S$. bovis $(\mathrm{p}<0,05)$ quando as instalações da sala de ordenha eram feitas de madeira.

Houve diferença significativa $(p=0,04)$ entre os grupos de produtores que realizam ordenha manual e mecânica com relação às contagens de S. aureus: nas UPL com ordenha manual houve maiores contagens do agente. A ordenha manual também afetou negativamente os níveis de CCS $(p=0,003)$, uma vez que houve maiores índices de mastite no rebanho que é ordenhado dessa maneira (Tabela 4). 
Tabela 3. Estimativa de risco relativo (Odds ratio) de ocorrência de bactérias do gênero Streptococcus em leite de tanque resfriador, relacionada com técnicas de manejo e instalações do gado leiteiro em 274 propriedades rurais da região sul do Rio Grande do Sul, no ano de 2012.

\begin{tabular}{|c|c|c|c|c|c|}
\hline Fatores & & S. agalactiae & S. dysgalactiae & S. uberis & S. bovis \\
\hline Ordenha & Manual X Mecânica & $3,205^{*}$ & 1,342 & 0,535 & 0,408 \\
\hline Pré-dipping & Sim X Não & 0,860 & 0,698 & 0,472 & 1,699 \\
\hline \multirow{3}{*}{ Secagem } & Papel -1 & $1 \times 2-0,335$ & $1 \times 2-0,839$ & $1 \times 2-0,712$ & $1 \times 2-0,652$ \\
\hline & Pano - 2 & $1 \times 3-1,618^{*}$ & $1 \times 3-0,442 *$ & $1 \times 3-1,277$ & $1 \times 3-0,542$ \\
\hline & Nada - 3 & $2 \times 3-3,113 *$ & $2 \times 3-2,618$ & $2 \times 3-0,708$ & $2 \times 3-0,411$ \\
\hline $\begin{array}{c}\text { Material da sala } \\
\text { de ordenha }\end{array}$ & Madeira X Alvenaria & 0,570 & 0,715 & 1,142 & $2,821^{*}$ \\
\hline $\begin{array}{l}\text { Piso da sala de } \\
\text { ordenha }\end{array}$ & Terra X Cimento & 0,929 & 1,058 & 1,415 & 0,853 \\
\hline
\end{tabular}

*valores estatisticamente diferentes $(\mathrm{p}<0,05)$.

Fonte: Elaboração dos autores.

Tabela 4. Contagens de micro-organismos, bacteriana total e de células somáticas, de acordo com a técnica de manejo adotada em unidades de produção leiteira de municípios da região sul do Rio Grande do Sul, no ano de 2012.

\begin{tabular}{lccccccc}
\hline & \multicolumn{2}{c}{ Ordenha } & \multicolumn{3}{c}{ Secagem do teto } & \multicolumn{2}{c}{ Pré-dipping } \\
\cline { 2 - 7 } & manual & mecânica & papel toalha & pano & nenhum & SIM & NÃO \\
\hline Staphylococcus & $3,09 \times 10^{4} \mathrm{a}$ & $7,8 \times 10^{4} \mathrm{a}$ & $2,52 \times 10^{4} \mathrm{a}$ & $4,99 \times 10^{4} \mathrm{a}$ & $1,34 \times 10^{5} \mathrm{a}$ & $3,59 \times 10^{4} \mathrm{a}$ & $6,36 \times 10^{4} \mathrm{~b}$ \\
S. aureus & $3,65 \times 10^{3} \mathrm{a}$ & $5,6 \times 10^{3} \mathrm{~b}$ & $5,4 \times 10^{3} \mathrm{a}$ & $4,11 \times 10^{3} \mathrm{a}$ & $6,62 \times 10^{3} \mathrm{a}$ & $5,8 \times 10^{3} \mathrm{a}$ & $4,71 \times 10^{3} \mathrm{a}$ \\
Enterobactérias & $1,21 \times 10^{6} \mathrm{a}$ & $4,86 \times 10^{5} \mathrm{a}$ & $1,52 \times 10^{5} \mathrm{a}$ & $1,06 \times 10^{6} \mathrm{a}$ & $7,85 \times 10^{5} \mathrm{a}$ & $2,55 \times 10^{5} \mathrm{a}$ & $8,67 \times 10^{5} \mathrm{a}$ \\
CCS & $6,54 \times 10^{5} \mathrm{a}$ & $4,64 \times 10^{5} \mathrm{~b}$ & $4,72 \times 10^{5} \mathrm{a}$ & $6,11 \times 10^{5} \mathrm{a}$ & $4,37 \times 10^{5} \mathrm{a}$ & $4,82 \times 10^{5} \mathrm{a}$ & $5,5 \times 10^{5} \mathrm{a}$ \\
CBT & $4,31 \times 10^{6} \mathrm{a}$ & $2,7 \times 10^{6} \mathrm{a}$ & $2,33 \times 10^{6} \mathrm{a}$ & $3,4 \times 10^{6} \mathrm{a}$ & $4,87 \times 10^{6} \mathrm{a}$ & $1,26 \times 10^{6} \mathrm{a}$ & $3,72 \times 10^{6} \mathrm{a}$ \\
\hline
\end{tabular}

Letras diferentes na mesma linha significam diferenças estatísticas calculadas pelo teste $\mathrm{T}$ de Student com nível de significância de $95 \%(p<0,05)$.

Fonte: Elaboração dos autores.

As análises de risco também foram realizadas para a presença de Escherichia coli e para os fungos pesquisados, porém não houve comprovação estatística.

\section{Discussão}

Em todas as amostras de leite cru avaliadas, houve crescimento de Staphylococcus spp. Esse gênero de micro-organismos é encontrado no ambiente, mas também pode ser causador de infecções intramamárias. Lamaita et al. (2005), encontraram contagem média de Staphylococcus spp. que variou de $1,0 \times 10^{5}$ a 2,5 x $10^{7} \mathrm{UFC} / \mathrm{mL}$, no estado de Minas
Gerais. A presença de $S$. aureus em leite representa um perigo à saúde do consumidor, pelo potencial patogênico dessa bactéria que é produtora de importantes enterotoxinas termoestáveis. Segundo Bergdoll (1990), o leite com contagens a partir de $10^{5} \mathrm{UFC} / \mathrm{mL}$ pode conter micro-organismos em quantidade suficiente para sintetizar enterotoxinas. No presente estudo, o leite produzido em algumas UPL nos municípios de Pelotas, Canguçu e Cerrito apresentaram contagens acima desse valor. $\mathrm{Na}$ pesquisa de $S$. aureus no leite cru, realizada por Picoli et al. (2006), a quantidade média do microorganismo presente no leite foi de $8,47 \times 10^{3} \mathrm{UFC} /$ $\mathrm{mL}$, na região de Porto Alegre/RS. 
A qualidade do leite cru também está relacionada com o grau de contaminação inicial (bactérias oriundas do exterior e interior da glândula mamária) e com o binômio tempo/temperatura desde a ordenha até o processamento (XAVIER et al., 2000). A pesquisa dos micro-organismos da família Enterobacteriaceae, incluindo Escherichia coli, indica as condições higiênicas e sanitárias do processo de obtenção e armazenamento do leite. O isolamento de E. coli reflete uma preocupante realidade, pois uma grande quantidade do leite produzido é comercializado sem nenhum tipo de tratamento térmico (MEZZADRI, 2012). Além disso, a presença de $E$. coli significa um risco à saúde do consumidor, pois alguns de seus sorotipos tem grande potencial patogênico podendo causar severas enterites ao ser humano e aos animais (RIBEIRO et al., 1999; RADOSTITS el al., 2002).

Quanto aos isolamentos das bactérias do gênero Streptococcus, destaca-se S. agalactiae que é um organismo altamente contagioso, capaz de causar fibrose e abcessos na glândula mamária, além de elevar muito a CCS. Sua presença preocupa também pelo aspecto da saúde pública, pois é causa importante de meningites e septicemia neonatal (TRABULSI; ALTERTHUM, 2005). A presença de $S$. agalactiae no leite do tanque resfriador é indicativo de mastite causada por esse patógeno, já que não sobrevive fora do tecido infectado. Já $S$. dysgalactiae se comporta de forma semelhante ao $S$. agalactiae na forma pela qual se dissemina em um rebanho (SILVA et al., 2010) e, quando isolado de amostras de leite, especialmente de tanque resfriador, pode ser oriundo de outras fontes ambientais, como o solo e pelagem dos animais (BRITO et al., 1998).

Aprevalência encontradade S. uberisera esperada, visto que este micro-organismo encontra-se em todo ambiente de ordenha, devido à contaminação fecal das vacas que abrigam o organismo no rúmen. Este micro-organismo torna-se um patógeno importante quando o úbere saudável entra em contato com ambientes contaminados (REBHUN, 2000). No tanque resfriador, junto de diversas outras espécies bacterianas, $S$. uberis não prevalece, pois não é um bom competidor (DOGAN; BOOR, 2004). Desta forma, elevados níveis de $S$. uberis em leite com bom resfriamento são indicadores de problemas de mastite no rebanho.

Os fatores encontrados, que podem influenciar a ocorrência das bactérias do gênero Streptococcus spp., são demonstrados na Tabela 3.

A ordenha manual aumentou as chances de ocorrência de S. agalactiae e, sendo este microorganismo incapaz de sobreviver fora do organismo animal, esse resultado demonstra a importância do correto manejo de obtenção do leite, principalmente por parte do ordenhador, que pode ser o responsável pela transmissão do patógeno através de suas mãos (SANTOS; FONSECA, 2007). Ainda com relação a este agente, a forma como é realizada a secagem do teto antes da ordenha, representa um fator de risco a sua ocorrência. A utilização do pano aumentou as chances de ocorrência em 3,1 vezes, comparado ao papel toalha. Isso ocorre devido ao fato do pano ser de uso único a todos os animais, veiculando patógenos e aumentando os novos casos de mastite na propriedade. Já a comparação entre a utilização do papel toalha e a ausência de secagem, demonstra 1,6 vezes mais chances de ocorrência com o uso do papel. Isso pode ser explicado pela má utilização do papel toalha. Deve-se utilizar uma folha de papel para cada teto, caso contrário esta prática se assemelhará ao uso do pano na transmissão de agentes pelo rebanho. Quanto ao $S$. dysgalactiae, o papel toalha age como um fator de proteção à ocorrência deste agente $(\mathrm{OR}=0,442)$. S. dysgalactiae pode ser encontrado no ambiente e na superfície da pele (BRITO et al., 1998) e, neste caso, a não secagem do teto pode influenciar na sua transmissão.

S. bovis é um agente que coloniza o trato gastrointestinal de ruminantes e também de humanos (BARCELOS, 2010) e está no ambiente. Este fato pode explicar a maior pré-disposição deste agente 
$(2,8$ vezes mais chances $(\mathrm{p}<0,05))$ (Tabela 3$)$ quando as instalações da sala de ordenha eram feitas de madeira, dificultando a higienização.

A ordenha manual afetou negativamente a CCS das UPL avaliadas e, esses resultados concordam com os de Saran Netto et al. (2009) que também encontrou diferença significativa para a variável CCS, em estudo comparativo da qualidade do leite de acordo com a ordenha.

Já o pré-dipping atuou prevenindo a ocorrência de Staphylococcus spp. diminuindo as contagens no leite cru. A desinfecção pré- ordenha desempenha papel fundamental na prevenção da mastite, pois o equipamento de ordenha pode transmitir patógenos de um quarto afetado para outro sadio, caso o primeiro não tenha sofrido desinfecção prévia (PICOLI et al., 2008).

Quanto às pesquisas de fungos e Escherichia coli, não houve significâncias estatísticas ( $>0.05$ ) quanto aos fatores de risco, porém não se pode negligenciar estes patógenos. A presença de fungos no leite cru merece destaque, uma vez que muitos destes micro-organismos são agentes de micoses oportunistas e/ou produtores de micotoxinas, que podem comprometer a qualidade do leite e a saúde humana (MELVILLE et al., 2006). Neste estudo, os gêneros fúngicos mais prevalentemente isolados foram Candida sp., Trichosporum sp., Aspergillus sp. e Cryptococcus sp. (Tabela 2). Todos eles são patógenos importantes na etiologia das mastites, como também em outras enfermidades de importância médico-veterinária e de saúde pública. Apesar da importância de fungos dos gêneros Rhodothorula sp. e Geotrichum sp.em mastite bovina (CHAHOTA et al., 2001), estes microorganismos foram isolados em menor proporção (dados não mostrados). Segundo Cousins e Bramley (1981), os isolados fúngicos a partir de amostras de leite provenientes de tanques resfriadores podem ter origem a partir de úberes infectados, da superfície dos tetos ou do equipamento de ordenha mal higienizado. Portanto, medidas de manejo de ordenha adequadas e a correta higienização do ambiente e equipamentos de ordenha, são fatores que podem contribuir para minimizar a ocorrência de mastites por fungos bem como reduzir a contaminação durante o processo de ordenha.

Dentre os agentes fúngicos, o gênero Candida sp. foi o mais isolado neste estudo $(15,7 \%)$, o que corrobora com os dados obtidos por Melville et. al (2006), que em estudo semelhante obteve este gênero como o mais prevalente em leite proveniente de tanques resfriadores. Cabe ressaltar, no entanto, que as amostras foram coletadas de tanques resfriadores, o que não garante que os isolados sejam provenientes de quartos mamários infectados.

\section{Conclusões}

Em leite de tanques resfriadores são encontrados micro-organismos das mais variadas espécies, porém com os resultados obtidos a partir deste estudo, conclui-se que as técnicas de manejo de ordenha influenciam na qualidade microbiológica do leite.

O tipo de ordenha, a realização ou não do prédipping, a forma como é realizada a secagem do teto e as instalações da sala de ordenha são os fatores que mais influenciam na ocorrência de agentes infecciosos no leite. Técnicas mais precárias de manejo influenciam negativamente, elevando as contagens de micro-organismos presentes no leite de tanques resfriadores e os riscos de ocorrência de micro-organismos importantes na etiologia das mastites.

Estreptococos ambientais têm maior risco de ocorrência em locais cujas instalações são precárias. Já estreptococos contagiosos (S. agalactiae) têm sua ocorrência aumentada pelo manejo incorreto da ordenha.

\section{Referências}

ARAÚJO, W. N.; SILVA, M. H.; MARTINEZ, T. C. N.; BANAS, S. L. B.; SILVEIRA, V. F. Determinação do número de fungos filamentosos e leveduras no 
queijo Minas comercializado na região metropolitana de Salvador - Bahia. Revista Brasileira de Saúde e Produção Animal, Salvador, v. 2, n. 1, p. 10-14, 2001.

BARBALHO, T. C. F.; MOTA, R. A. Isolamento de agentes bacterianos envolvidos em mastite subclínica bovina no estado de Pernambuco. Revista Brasileira de Saúde e Produção Animal, Salvador, v. 2, n. 2, p. 31-36, 2001.

BARCElOS, A. M.; TEIXEIRA, M. A.; ALVES, L. S.; VIEIRA, M. A.; BEDIM, M. L.; RIBEIRO, N. A. Endocardite infecciosa por Streptococcus bovis em paciente com carcinoma colônico. Arquivos Brasileiros de Cardiologia, Ribeirão Preto, v. 95, n. 3, p. 88-90, 2010.

BERGDOLL, M. S. Staphylococcal food poisoning. In: CLIVER, D. O. (Ed.). Foodborne diseases. London: Academic, 1990. p. 87-106.

BRASIL. Ministério da Agricultura, Pecuária e Abastecimento. Instrução Normativa $\mathrm{n}^{\circ}$ 62, de 29 de dezembro de 2011. Aprova o regulamento técnico de produção, identidade e qualidade do leite tipo $\mathrm{A}$, o regulamento técnico de identidade e qualidade de leite cru refrigerado, o regulamento técnico de identidade e qualidade de leite pasteurizado e o regulamento técnico da coleta de leite cru refrigerado e seu transporte a granel, em conformidade com os anexos desta instrução normativa. Diário Oficial [da] República Federativa do Brasil, Brasília, 31 dez. de 2011. Seção 1, p. 6.

BRESSAN, M. Práticas de manejo sanitário em bovinos de leite. Juiz de Fora: Embrapa/CNPGL, 2000. 65 p.

BRITO, M. A. V. P.; BRITO, J. R. F.; SOUZA, H. M.; VARGAS, O. L. Avaliação da sensibilidade da cultura de leite do tanque para isolamento de agentes contagiosos da mastite bovina. Pesquisa Veterinária Brasileira, Seropédica, v. 18, n. 1, p. 39-44, 1998.

CERQUEIRA, M. M. O. P.; PICININ, L. C. A.; FONSECA, L. M.; SOUZA, M. R.; LEITE, M. O.; PENNA, C. F. A. M. Qualidade da água e seu impacto na qualidade microbiológica do leite. In: MESQUITA, A. J.; DURR, J. W.; COELHO, K. O. Perspectivas e avanços da qualidade do leite no Brasil. Goiânia: Talento, 2006. p. 273-290.

CHAHOTA, R.; KATOCH, R.; MAHAJAN, A.; VERMA, S. Clinical bovine mastitis caused by Geotrichum candidum. Veterinarski Arhiv, Zagreb, v. 71, n. 4, p. 197, 2001.

COUSINS, C. M.; BRAMLEY, A. J. The microbiology of raw milk. In: ROBINSON, R. K. Dairy microbiology. London: Applied Science Publishers, 1981. p. 119-163.
DOGAN, B.; BOOR, K. J. Short communication: groeth characteristics of Streptococcus uberis in UHT-treated milk. Journal of Dairy Science, Madison, v. 87, n. 4, p. 813-815, 2004.

FONSECA, L. F. L.; SANTOS, M. V. Qualidade do leite e controle da mastite. São Paulo: Lemos Editorial, 2000. $175 \mathrm{p}$.

LAMAITA, H. C.; CERQUEIRA, M. M. O. P.; CARMO, L. S.; SANTOS, D. A.; PENNA, C. F. A. M.; SOUZA, M. R. Contagem de Staphylococcus sp. e detecção de enterotoxinas estafilocócicas e toxina da síndrome do choque tóxico em amostras de leite cru refrigerado. Arquivo Brasileiro de Medicina Veterinária e Zootecnia, Belo Horizonte, v. 57, n. 5, p. 702-709, 2005.

MELVILLE, P. A.; RUZ-PEREZ, M.; YOKOIA, E.; BENITES, N. R. Ocorrência de fungos em leite cru proveniente de tanques de refrigeração e latões de propriedades leiteiras, bem como de leite comercializado diretamente ao consumidor. Arquivos do Instituto Biológico, São Paulo, v. 73, n. 3, p. 295-301, 2006.

MEYER, N. S.; PICOLI, T.; PETER, C. M.; CZERMAINSKI, L. A.; MARQUES, L. T.; ZANI, J. L. Micro-organismos isolados de quartos mamários com mastite sub-clínica em unidades de produção leiteira de Pelotas/RS. In: CONGRESSO DE INICIAÇÃO CIENTÍFICA DA UNIVERSIDADE FEDERAL DE PELOTAS, 22., 2013, Pelotas. Anais... Pelotas, 2013. Disponível em: <http://cti.ufpel.edu.br/cic/ arquivos/2013/CA_00674.pdf $>$. Acesso em: 29 abr.2014.

MEZZADRI, F. P. Análise da conjuntura agropecuária ano 2011/12. Curitiba: DERAL/SEAB, 2012. Disponível em: $\quad<$ http://www.agricultura.pr.gov.br/arquivos/File/ deral/Prognosticos/leite_2012.pdf $>$. Acesso em: $02 \mathrm{mar}$. 2013.

PICOLI, S. U.; BESSA, M. C.; CASTAGNA, S. M. F.; GOTTARDI, C. P. T.; SCHIMDT, V.; CARDOSE, M. Quantificação de coliformes, Staphylococcus aureus e mesófilos presentes em diferentes etapas da produção de queijo frescal de leite de cabra em laticínios. Revista Ciência e Tecnologia de Alimentos, Campinas, v. 26, n. 1, p. 64-69, 2006.

PICOLI, T.; SCHMITT, B.; SCHNEIDER, J. R.; ZANI, J. L. Práticas de manejo e ocorrência de Corynebacterium bovis em propriedades leiteiras no município de PelotasRS. In: CONBRAVET CONGRESSO BRASILEIRO DE MEDICINA VETERINÁRIA, 35., Gramado. Anais... Gramado, 2008. Disponível em: <http://www.sovergs. com.br/conbravet2008/anais/cd/resumos/R0675-1.pdf>. Acesso em: 05 jun. 2013. 
PRESCOTT, L. M.; HARLEY, J. P.; KLEIN, D. A. Microbiology. $5^{\text {th }}$ ed. New York: The McGraw-Hill Companies, 2002. 1026 p.

QUINN, P. J.; MARKEY, B. K.; CARTER, M. E.; DONNELLY, W. J.; LEONARD, F. C. Microbiologia veterinária e doenças infecciosas. Porto Alegre: Artmed, 2005. $512 \mathrm{p}$.

RADOSTITS, O. M.; GAY, C. C.; BLOOD, W. C.; HINCLIFF, K. W. Clínica veterinária: um tratado de doenças dos bovinos, ovinos, suínos, caprinos e eqüinos. 9. ed. Rio de Janeiro: Guanabara Koogan, 2002. 1770 p.

REBHUN, W. C. Doenças do gado leiteiro. São Paulo: Editora Roca, 2000. 642 p.

RIBEIRO, M. E. R.; PETRINI, L. A.; AITA, M. F.; BALBINOTTI, M.; TUMPF JÚNIOR, W.; GOMES, J. F.; SCHRAMM, R. C.; MARTINS, P. R.; BARBOSA, R. S. Relação entre mastite clínica, subclínica infecciosa e não infecciosa em unidades de produção leiteira na região sul do Rio Grande do Sul. Revista Brasileira de Agrociência, Pelotas, v. 9, n. 3, p. 287-290, 2003.

RIBEIRO, M. G.; SILVA, E. O. T. R.; PINTO, J. P. A. N. Escherichia coli O157:H7. De hambúrguer, leite e outros gêneros alimentícios à colite hemorrágica e síndrome urêmica hemolítica. Revista Higiene Alimentar, São Paulo, v. 13, n. 66-67, p. 88-99, 1999.

RUZ-PERES, M.; YOKOYA, E.; PASSARELLI, D.; CANTARINO, S. C.; BENITES, N. R.; MELVILLE, P. A. Pesquisa de fungos no leite de tanques de refrigeração de propriedades de exploração leiteira. Arquivos do Instituto Biológico, São Paulo, v. 71, p. 663-665, 2004.
SANTOS, M. V.; FONSECA, L. F. L. Estratégias para controle de mastite e melhoria da qualidade do leite. São Paulo: Manole, 2007. 328 p.

SARAN NETTO, A.; FERNANDES, R. H. R.; AZZI, R.; LIMA, Y. V. R. Estudo comparativo da qualidade do leite em ordenha manual e mecânica. Revista do Instituto de Ciências da Saúde, v. 27, p. 345-349, 2009.

SILVA, M. V. M.; NOGUEIRA, J. L.; PASSOS, C. C.; FERREIRA, A. O.; AMBRÓSIO, C. E. A mastite interferindo no padrão de qualidade do leite: uma preocupação necessária. Revista Científica Eletrônica de Medicina Veterinária, Garça, Ano VIII, n. 14, 2010.

STATISTICAL ANALYSIS SYSTEM INSTITUTE - SAS INSTITUTE. SAS/Stat user's guide. Version 9.1.Cary: SAS Institute, 2004.

TRABULSI, L. R.; ALTERTHUM, F. Microbiologia. 5. ed. São Paulo: Atheneu, 2005. 780 p.

TURNES, C. G. Agentes de mastitis em leche total de estabelecimiento. Revue de Médecine Vétérinaire, Toulouse, v. 51, n. 1, p. 43-48, 1970.

WATTS, J. L. Etiological agents of bovine mastitis. Veterinary Microbiology, Barcelona, v. 16, n. 1, p. 41-66, 1988.

XAVIER, L. S.; PINTO, S. M.; ABREU, L. R.; MOURA, C. F. M.; CLEMENTE, P. R. Coleta de leite em latões e a granel: Estudos de casos. Revista Instituto Lacticinio "Cândido Tostes", Juiz de Fora, v. 55, n. 314, p. 22-26, 2000. 